TI 2011-149/4

Tinbergen Institute Discussion Paper

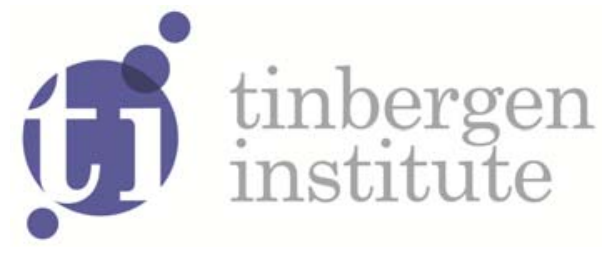

\title{
Are Chinese Individuals prone to Money Illusion?
}

Heleen Mees ${ }^{7}$

Philip Hans Franses 2

1 New York University, Wagner Graduate School of Public Service, United States;

${ }^{2}$ Erasmus School of Economics, Erasmus University Rotterdam, and Tinbergen Institute, the Netherlands. 
Tinbergen Institute is the graduate school and research institute in economics of Erasmus University Rotterdam, the University of Amsterdam and VU University Amsterdam.

More TI discussion papers can be downloaded at http://www.tinbergen.nl

Tinbergen Institute has two locations:

Tinbergen Institute Amsterdam

Gustav Mahlerplein 117

1082 MS Amsterdam

The Netherlands

Tel.: +31(0)205251600

Tinbergen Institute Rotterdam

Burg. Oudlaan 50

3062 PA Rotterdam

The Netherlands

Tel.: +31(0)10 4088900

Fax: $+31(0) 104089031$

Duisenberg school of finance is a collaboration of the Dutch financial sector and universities, with the ambition to support innovative research and offer top quality academic education in core areas of finance.

DSF research papers can be downloaded at: http://www.dsf.nl/

Duisenberg school of finance

Gustav Mahlerplein 117

1082 MS Amsterdam

The Netherlands

Tel.: +31(0)20 5258579 


\title{
Are individuals in China prone to money illusion?
}

\author{
Heleen Mees* $\quad$ Philip Hans Franses $†$
}

\begin{abstract}
We replicate the landmark study of Shafir, Diamond and Tversky (1997) to examine whether individuals in China are prone to money illusion. We find that money illusion is prevalent in China as well. Respondents in the Chinese sample are often somewhat more likely to base decisions on the real monetary value of economic transactions compared to respondents in the U.S. sample. If asked explicitly to evaluate a transaction in terms of happiness or satisfaction, instead of economic terms, money illusion among respondents in the Chinese sample is comparable to money illusion among respondents in the U.S. sample.
\end{abstract}

C91 - Laboratory, Individual behavior

210 - experimental economics

220 - financial behavior

390 - psychology of money

* Adjunct Associate Professor at New York University Wagner Graduate School of Public Service

† Professor at Erasmus School of Economics, Erasmus University

WORKING PAPER - FINAL VERSION 
“It isn’t the sum you get, it’s how much you can buy with it, that's the important thing; and it’s that that tells whether your wages are high in fact or only high in name.” Mark Twain A Connecticut Yankee in King Arthur's Court (1889)

\section{Introduction}

The term "money illusion” refers to a tendency to think in terms of nominal monetary values rather than real monetary values. The relevant literature presents various experiments to establish whether people are subject to money illusion, and various potential psychological causes that underlie this phenomenon. In this paper we examine how respondents in Beijing, China, respond to changes in inflation and prices, using the questionnaire designed and implemented by Shafir, Diamond and Tversky (1997).

We set out to examine whether there is money illusion in China. In addition, we examine whether respondents in China tend to think in different terms about economic transactions than respondents in the United States, where the original questionnaire was held. Shafir, Diamond and Tversky (1997) conclude on the basis of the responses to the survey that money illusion is a widespread phenomenon in the United States.

Our survey-based findings suggest that money illusion is widespread in China just as it is in the United States. Respondents in the Chinese sample are often somewhat less prone to money illusion than respondents in the United States. If asked explicitly to evaluate an economic transaction in terms of happiness or satisfaction, respondents in the Chinese sample are as likely as respondents in the United States to prefer the transaction with the highest nominal monetary value instead of the economic transaction with the highest real monetary value.

As recent research shows that money illusion may play a much greater and more disruptive role in the economy than economists have allowed for in the past, both with regard 
to the functioning of the labor market (Mees, 2011) as well as the housing market

(Brunnermeier and Julliard (2008), Bernanke (2010)), it is important to shed further light on the phenomenon in all its forms, and its implications for economic theory.

The outline of our paper is as follows. We first give a review of the relevant economic literature on money illusion. Next, in Section 3, we discuss potential occurrences of money illusion in China. Section 4 deals with the main contribution of our study, which is the survey and the responses, for which we interviewed many Chinese individuals. This unique dataset allows us to answer the question in the title. Section 5 includes a table with the core results of our research. In Section 6 we conclude with a discussion of the main results and we suggest avenues for further research.

\section{Literature overview}

In the early '20s John Maynard Keynes coined the term 'money illusion' to describe the tendency of people to be fooled by thinking in nominal rather than real terms, ignoring the effect of inflation on the purchasing power of money. A few years later Irving Fisher devoted an entire book to the subject (Fisher, 1928). But even though money illusion was recognized early on in the economic literature (see also Leontief (1936) and Patinkin (1965)), mainstream economists have generally considered money illusion an anathema, as the phenomenon is irreconcilable with the rational expectations postulate (Fehr and Tyran, 2001, page 1239).

That did not prevent Shafir, Diamond and Tversky (1997) from drafting a fascinating questionnaire and collecting evidence that people often tend to think about economic transactions in both nominal and real terms, resulting in a bias toward a nominal evaluation. Shafir, Diamond and Tversky (1997) conclude on the basis of the responses to their survey that money illusion is a widespread phenomenon in the United States. 
There have also been more experimental approaches to money illusion. Using a pricing game with students in Switzerland as participants, Fehr and Tyran (2001) show that seemingly innocuous differences in payoff representation cause pronounced differences in nominal price inertia, indicating the behavioral importance of money illusion. Moreover, money illusion causes asymmetric effects of negative and positive nominal shocks. While nominal inertia is rather small after a positive shock, it is quite substantial after a negative shock.

Noussair, Richter, and Tyran (2012) find an asymmetry in the price response to inflationary and deflationary nominal shocks in a laboratory asset market situation as well. Fehr and Tyran (2008) show that deviations from individual rationality, i.e. money illusion on the part of individuals, can have important effects on aggregate outcomes. Daly, Hobijn, and Lucking (2012) show that downward nominal wage rigidities are the key reason that real wage growth has stayed relatively solid during the Great Recession in the face of high unemployment. The tendency of employers is to avoid cutting the dollar value of wages.

According to the Modigliani-Cohn hypothesis (1979), stock markets suffer from money illusion, discounting real cash flows at nominal discount rates (1979). When inflation is high (low), the rational equity-premium expectation is higher (lower) than the market's subjective expectation, and the stock market is undervalued (overvalued). Cohen et al. (2005) show that the money-illusion hypothesis not only has implications for the pricing of the aggregate stock market relative to Treasury bills, but also for the pricing of risky stocks relative to safe stocks.

Brunnermeier and Julliard (2008) show that a reduction in inflation can fuel run-ups in housing prices if people suffer from money illusion. They mistakenly assume that real and nominal interest rates move in lockstep. Hence, they wrongly attribute a decrease in inflation to a decline in the real interest rate and consequently underestimate the real cost of future 
mortgage payments. According to Brunnermeier and Julliard (2008), inflation and nominal interest rates explain a large share of the mispricing in the U.K. housing market from 1966 to 2004. Genesove and Mayer (2001) show that loss aversion determines seller behavior in the housing market. Their findings suggest that sellers are averse to realizing (nominal) losses and help explain the positive price-volume correlation in real estate markets.

Bernanke (2010) asserts that mortgages with exotic features, which lowered monthly mortgage installments significantly, are to blame for the U.S. housing boom in the 2000s. This suggests not so much money illusion on the part of economic subjects, but rather money delusion. Regardless of the veracity of Bernanke's claim (mortgages with exotic features accounted for less than 5 percent of total mortgage originations from 2000 - 2006 (Mees, 2011), Brunnermeier and Julliard (2008) find for the United States a similar link between housing market mispricing and inflation as for the United Kingdom.

Akerlof and Shiller (2009, Ch. 4) and Fehr (2007) discuss occurrences of money illusion in daily life and its impact on markets.

In view of the findings of Brunnermeier and Julliard (2008), Bernanke (2010) and Fehr and Tyran (2008), money illusion may be of greater economic significance than most mainstream economists allow for because of the interaction between the housing market, stock market and the real economy. Given its potential impact on the functioning of the economy, it is of interest to see whether money illusion also holds for China.

\section{The occurrence of money illusion in China}

Shafir, Diamond and Tversky (1997) distinguish three phenomena in the real economy that suggest the existence of money illusion on the part of economic subjects. ${ }^{1}$ One is that prices are sticky. A second is that indexing does not occur in contracts and laws in times of relatively

\footnotetext{
${ }^{1}$ See Shafir, Diamond and Tversky (1997) for an in-depth discussion of money illusion in the United States.
} 
low inflation, as theory would predict. The third occurrence is through conversation, rather than behavior, that is, people talk and write in ways that seem to indicate some confusion between money's nominal and real value. We would like to add a fourth phenomenon to the previous ones, which occurs at the intersection of asset markets and the real economy, and that is that parameters from the real economy (nominal interest rates, dividends) are used as yardsticks for asset pricing (Modigliani-Cohn hypothesis).

Within the context of China, which still has abundant characteristics of a centrally planned economy, price stickiness may primarily be the result of price and quantity controls. ${ }^{2}$ Kim, Nan, Wan and Wu (2011), for example, find that significant price stickiness exists for U.S. imports from China. The mean duration is 11 months compared to 7 months for China imports from the United States. The price stickiness of U.S. imports from China however declined after June 2005, when China switched from a fixed exchange rate regime to a managed floating one (Kim et al. (2011)).

Compared to the United States and Europe, you find in China less indexed contracts, which should not come as a surprise as China is still very much an economy in transition. Even in developed economies you do not find indexed contracts in nearly as many places as economic theory suggests they should be found. According to Shiller (1997), the history of the United States largely seems to be one of missed opportunities for indexation, with the possible exception of labor markets. U.S. debt contracts rarely protect creditors against inflation. As China is the largest foreign holder of U.S. treasuries and agency bonds, it is worthwhile to note that only few are so-called treasury inflation-protected securities (TIPS).

Liu (2010) suggests that money illusion may account to a large extent for the mechanism of sharp run-ups in stock prices in China during the low inflation period. There is no similar research available for China’s still young housing market. Though Hong and Chen

\footnotetext{
${ }^{2}$ In an attempt to dampen inflation, the Chinese government in 2010 announced price controls and said it would put state commodity reserves (grains, edible oils and sugar) on the market when necessary in order to guarantee supplies (China Daily, November 17, 2010).
} 
(2010) conclude that there is a strong correlation between mortgage credit and housing prices, the variation in inflation and mortgage rates over 10 years is insufficient to find a link between housing market mispricing and inflation.

\section{The survey}

In this section we will examine whether money illusion is prevalent in China as well. For that purpose we replicate a well-established survey, which was implemented in Shafir, Diamond and Tversky (1997). We translated the survey questions to (simplified) Chinese, using Chinese names and adapting prices and dates to present respondents with realistic choices in the context of Beijing anno 2011.

Shafir, Diamond and Tversky collected responses from people in Newark International Airport and in two New Jersey shopping malls. In addition, they surveyed undergraduate students at Princeton University. As the responses from these groups did not differ significantly, Shafir, Diamond and Tversky reported the data in a combined format. ${ }^{3}$

We collected responses from undergraduate students from the economic departments at Peking University (1/2) and Tsinghua University in Beijing (1/4), as well as from workers at Alibaba, a tech company with a large office in Beijing (1/4). ${ }^{4}$ The undergraduate students were about 19 - 21 years old and the Alibaba workers were in their mid twenties and early thirties. The students were of both sexes, while the majority of Alibaba workers were male.

The survey questions were in part handed out on paper sheets (3/4) and in part collected through an Internet survey tool (1/4). More than 400 respondents participated in the survey. For each problem below we will report the exact number of respondents. Where appropriate, respondents were presented with only one version of the problem at hand. With

\footnotetext{
${ }^{3}$ Shafir, Diamond and Tversly present their results as if they are representative for the United States. It is , however, debatable whether airline passengers and students of Princeton University are indeed representative of the whole population.

${ }^{4}$ We decided not to collect responses in public places, as it was highly unlikely that we would get official clearance from Chinese authorities amid the popular uprisings in the Arab world at the time.
} 
respect to problem 1, for example, we asked one group of respondents to make a decision based on economic terms, another group of respondents to make a decision in terms of happiness and still another group of respondents to make a decision based on job attractiveness. Problem 4 was presented in six different versions to six different groups.

We looked on a case-by-case basis what prices would present respondents in Beijing, China with realistic choices compared to respondents in Shafir et al.’s sample. ${ }^{5}$ Our starting point was an exchange rate of $¥ / \$=4$, which was approximately the real effective exchange rate at the time. However, Western-style products are relatively expensive in China, which explains the exchange rate in problem 3 and 5.

Although neither sample is representative of the respective general populations, we believe that it is nonetheless worthwhile to compare the results of Shafir, Diamond and Tversky (SDT) with our results (MF). Shafir et al. indicate that their sample is drawn from people in New Jersey shopping malls and Newark airport as well as from undergraduate students at Princeton University without specifying the number of respondents in each group. ${ }^{6}$ Since general background information such as gender, age and profession is lacking in their study, we cannot determine the differences between their and our sample using statistical tests.

We use the non-parametric Pearson Chi-square tests with exact two-sided p values (as computed using IBM SPSS Statistics software, version 20). The tests are based on the actual frequencies (and not on the fractions), although we have transformed the MF-dataset into $\mathrm{n}^{*}$ datasets with the same sample size as the SDT-dataset. We assume $10 \%$ noise in the data, because respondents may just have been careless in responding or mistaken rather than being

\footnotetext{
5 'We' are two Chinese translators/assistants, a Russian/Israeli small-business owner in Beijing and the first author.

${ }^{6}$ A repeated request to the authors for information about the number of respondents in each group was left unanswered.
} 
prone to money illusion. A higher Chi-square score indicates in principle more money illusion, given a certain sample size.

In Appendix 1 (a) we present the actual outcomes (frequencies) of the SDT- and MFsurveys. In Appendix (b) the present the expected frequencies under the hypothesis of nomoney illusion and 10\% noise in the date. In Appendix (c) we compare the actual frequencies with the expected frequencies using the chi-square test. In Appendix (d) we again compare the actual frequencies with the expected frequencies using the chi-square test. This time we transformed the MF-dataset in a dataset with the same sample size as the SDT-dataset, so the Chi-square scores for the MF and SDT dataset indicate the level of money illusion.

In Appendix 2 (a) we present the Chi-square scores and p-values for the test whether the differences in the levels of money illusion in the U.S. sample and the Chinese sample are significant. In Appendix 2 (b) we test whether the results for respondents in the Chinese sample and the U.S. sample differ from randomness with a probability 0.5 in case of two choice options and 0.33 in case of three to see whether respondents were simply careless in responding. Our results suggest they were not.

We will discuss the outcomes for each problem below. A table with the core results will be presented in section 5 .

\section{A. Earnings}

The following survey presented three different groups of subjects with a scenario involving two individuals who receive raises in salary. One group was asked to rate the two protagonists’ salary raises on purely “economic terms;” a second group was asked to indicate which of the two they thought would be happier; the third group was asked to indicate which of the two was more likely to leave her present job for another position. (To the right of each 
option is the percentage of subjects who chose it, while the percentage in parentheses reflects the U.S.-based results given by Shafir, Diamond and Tversky).

\section{$\underline{\text { Problem } 1}$}

Consider two individuals, Li Li (李丽) and Wang Lan (王兰), who graduated from the same college a year apart. Upon graduation, both took similar jobs with publishing firms. Li Li started with a yearly salary of $¥ 120,000$. During her first year on the job there was no inflation, and in her second year Li Li received a 2\% (¥2400) rise in salary. Wang Lan also started with a yearly salary of $¥ 120,000$. During her first year on the job there was 4\% inflation, and in her second year Wang Lan received a 5\% (¥6000) rise in salary.

\section{Economic terms ( $\mathrm{N}=137)$ :}

As they entered their second year on the job, who was doing better in economic terms?

Li Li: $\quad 82 \% \quad$ (71\%) $\quad$ Wang Lan: $\quad 18 \% \quad$ (29\%)

Happiness ( $\mathrm{N}=138)$ :

As they entered their second year on the job, who do you think was happier?

Li Li: $\quad 39 \%^{+} \quad$ (36\%) $\quad$ Wang Lan: $61 \% \quad$ (64\%)

$\underline{\text { Job attractiveness }(\mathrm{N}=134) \text { : }}$

As they entered their second year on the job, each received a job offer from another firm. Who do you think was more likely to leave her present position for another job?
Li Li: $\quad 65 \%$
$(65 \%)$
Wang Lan: $\quad 35 \%$
$(35 \%)$ 
Just as in Shafir, Diamond and Tversky (1997), the majority of respondents in the Chinese sample correctly evaluate the above scenario in real rather than in nominal terms when economic terms are emphasized. When the emphasis is not on economic terms, but on terms like 'happiness' and 'job attractiveness' instead, the majority of respondents in the Chinese sample prefer the transaction that is most attractive in nominal terms. In this instance the outcome among respondents in the Chinese sample is similar to the outcome among respondents in the U.S. sample.

In case economic terms are emphasized, respondents in the Chinese sample are somewhat more likely to evaluate the scenario correctly than respondents in the U.S. sample (82\% versus 71\%), suggesting that respondents in the Chinese sample seem to understand the logic of inflation better. An alternative explanation may be that respondents in the U.S. sample have interpreted 'economic terms' more broadly to incorporate happiness and/or job attractiveness. Money illusion in the SDT sample and the MF sample is weak in case economic terms are emphasized and medium in case happiness and job attractiveness are emphasized (Section 5).

\section{B. Transactions}

Asked to assess of specific transactions instead of income, one third of the respondents in the Chinese sample fail to rank the transaction with the best outcome in real terms first, suggesting that people in China are susceptible to money illusion.

\section{Problem $2(\mathrm{~N}=415)$ :}

Suppose Zhang (张), Wang (王) and Li (李) each received an inheritance of ¥800,000 and each used it immediately to purchase a house. Suppose that each of them sold the house a year after buying it. Economic conditions, however, were different in each case: 
- When Zhang owned the house, there was a 25\% deflation - the prices of all goods and services decreased by approximately 25\%. A year after Zhang bought the house, he sold it for $¥ 616,000$ (23\% less than he paid).

- When Wang owned the house, there was no inflation or deflation - prices had not changed significantly during that year. He sold the house for $¥ 792,000$ (1\% less than he paid for it).

- When Li owned the house, there was $25 \%$ inflation - all prices increased by approximately 25\%. A year after he bought the house, Li sold it for $¥ 984,000$ (23\% more than he paid).

Please rank Zhang, Wang, and Li in terms of the success of their house-transactions. Assign ' 1 ' to the person who made the best deal and ' 3 ' to the person who made the worst deal.

\section{Zhang}

Nominal transaction: $-23 \%$

Real transaction: $\quad+2 \%$
Wang

$-1 \%$

$-1 \%$
$\underline{\mathrm{Li}}$

$+23 \%$

$-2 \%$

\section{$\underline{\text { Rank: }}$}

$\begin{array}{lllllll}1^{\text {st }} & 64 \% & (37 \%) & 12 \% & (17 \%) & 12 \% & (48 \%) \\ 2^{\text {nd }} & 13 \% & (10 \%) & 80 \% & (73 \%) & 18 \% & (6 \%) \\ 3^{\text {rd }} & 23 \% & (53 \%) & 8 \% & (10 \%) & 70 \% & (36 \%)\end{array}$


Compared to respondents in the U.S. sample, respondents in the Chinese sample were almost twice as likely to rank Zhang, who had the best deal in real terms but the worst deal in nominal terms, number 1 and also twice as likely to rank Li, who had the best deal in nominal terms but the worst deal in real terms, number 3. Respondents in the Chinese sample were also more likely than respondents in the U.S. sample to rank Wang correctly as the person who had the second best deal.

The differences in outcome are significant and suggest that respondents in the Chinese sample are either better at understanding the logic of inflation than their peers in the United States, or that they are more likely to conceive 'success' in economic terms while respondents in the United States are more likely to conceive 'success' in terms of happiness.

In a comparable set-up, Stephens and Tyran (2012) find that for about $60 \%$ of the subjects in Denmark evaluations are systematically biased by nominal representations. The subjects view real losses much more favorably when they involve nominal gains. Weber et al. (2009) included a problem comparable to Shafir et al.'s in a neurological test. A majority of their subjects in Germany chose the outcome associated with money illusion. The outcome in both Stephens and Tyran's as well as Weber et al. resemble the outcome that Shafir et al. find for the United States.

Weber et al. note that the medial prefrontal cortex, the area in the brain associated with the processing of rewards, is more stimulated in subjects that choose the outcome that is associated with money illusion.

\section{Problem 3:}

Changes in the economy often have an effect on people’s financial decisions. Imagine that China experienced unusually high inflation that affected all sectors of the 
economy. ${ }^{7}$ Imagine that within a six-month period all benefits and salaries, as well as the prices of all goods and services, went up by approximately 25\%. You now earn and spend $25 \%$ more than before.

Six months ago, you were planning to buy a leather armchair whose price during the 6month period went up from $¥ 3200$ to $¥ 4000$. Would you be more or less likely to buy the armchair now? $(\mathrm{N}=209)$

More: Same: Less:

$19 \% \quad(7 \%) \quad 29 \% \quad(55 \%) \quad 59 \%$

Six months ago, you were also planning to sell an antique desk you own, whose price during the 6-month period went up from $¥ 3200$ to $¥ 4000$. Would you be more or less likely to sell your desk now? $(\mathrm{N}=202)$

More:

Same:

Less:

$15 \%$

$(43 \%)$

$17 \%$

$(42 \%)$

$68 \%$

$(15 \%)$

Respondents in the U.S. sample more often indicate that nominal price changes will not affect their decision to buy or sell if real prices are unchanged compared to respondents in the Chinese sample. As far as the change in nominal prices does affect the decision, respondents in the U.S. sample indicate that they are more likely to sell at higher prices and less likely to buy at higher prices, suggesting money illusion.

\footnotetext{
${ }^{7}$ China in the late ' 80 s had a bout of high inflation (reaching 18\% in 1998) and in the mid '90s (reaching 24\% in 1994). Both were short-lived. Since the inflation rate in China hovers around $3 \%$.
} 
Respondents in the Chinese sample exhibit greater wariness both to buy as well as to sell at higher prices. This does not necessarily imply money illusion, although the Chi-square score of the MF-sample is much higher compared to the SDT-sample and we call it "strong" money illusion in the table in Secton 5. However, if it were indeed a case of money illusion, one would expect to see an asymmetry with regard to buying and selling, as we see in the U.S. sample. Perhaps respondents in the Chinese sample associate inflation more in general with economic hardship, which may result in economic paralysis at the level of the individual. Also, the price of the leather chair and the antique desk represents a larger share of annual income in Beijing, China compared to the United States, which may explain the reluctance to buy or sell.

\section{Contracts}

We asked subjects to consider signing a contract for a future transaction in an inflationary context, and to decide whether to agree upon a specified amount to be paid upon delivery or, instead, agree to pay whatever the price is at the future time. A risk-averse decision-maker is likely to prefer an indexed contract since, at a future time, a predetermined nominal amount may be worth more or less than its anticipated real worth. On the other hand, a nominally riskaverse decision-maker may perceive indexed contracting as riskier as the indexed amount may end up being greater or smaller in nominal terms than a fixed dollar amount (Shafir, Diamond and Tversky, 1997). The following problem was presented in China in the spring of 2011.

\section{Problem 4-1 (N=68):}

Imagine that you are the head of a corporate division located in Singapore that produces office computer systems. You are now about to sign a contract with a local firm for the sale of new systems, to be delivered in January 2013. 
These computer systems are currently priced at $¥ 4000$ a piece but, due to inflation, all prices, including production costs and computer prices, are expected to increase during the next couple of years. Experts' best estimate is that prices in Singapore two years from now will be about $20 \%$ higher, with an equal likelihood that the increase will be higher or lower than $20 \%$. The experts agree that a $10 \%$ increase in all prices is just as likely as a $30 \%$ increase.

You have to sign the contract for the computer systems now. Full payment will be made only upon delivery in January 2013. Two contracts are available to you. Indicate your preference between the contracts by checking the appropriate contract below:

One group of subjects chose between contracts A and B below.

Contracts framed in real terms:

Contract A: You agree to sell the computer systems (in 2013) at $¥ 4800$ a piece, no matter what the price of computer systems is at that time. Thus, if inflation is below $20 \%$ you will be getting more than the 2013-price, whereas if inflation exceeds $20 \%$ you will be getting less than the 2013-price. Because you have agreed on a fixed price, your profit level will depend on the rate of inflation.

$59 \%(19 \%)$

Contract B: You agree to sell the computer systems at 2013’s price. Thus, if inflation exceeds $20 \%$, you will be paid more than $¥ 4800$, and if inflation is below $20 \%$, you will be paid less than $¥ 4800$. Because both production costs and prices are tied to the rate of inflation, your "real" profit will remain essentially the same regardless of the rate of inflation.

41\% (81\%) 


\section{Problem 4-2 (N=70):}

Another group of subjects chose between contracts C and D:

Contracts framed in nominal terms:

Contract C: You agree to sell the computer systems (in 2013) at $¥ 4800$ a piece, no matter what the price of computer systems is at that time.

$53 \%(41 \%)$

Contract D: You agree to sell the computer systems at 2013’s price. Thus, instead of selling at $¥ 4800$ for sure, you will be paid more if inflation exceeds $20 \%$, and less if inflation is below $20 \%$.

$47 \%(59 \%)$

\section{Problem 4-3 (N=69):}

A third group of subjects was presented with the following, neutral version of the problem:

Contracts under a neutral frame:

Contract E: You agree to sell the computer systems (in 2013) at $¥ 4800$ a piece, no matter what the price of computer systems is at that time.

$60 \%(46 \%)$

Contract F: You agree to sell the computer systems at 2013’s prices. $40 \%(54 \%)$

We have run a second version of the above study; this time exploring people's contracting preferences as buyers rather than sellers. The following problem, along with the alternative 
framings of contract choices, is identical to those of Problem 4 except that the issue is now buying instead of selling.

Problem 4-4 (N=66):

Contracts framed in real terms:

Contract A’: You agree to buy the computer systems (in 2013) at $¥ 4800$ a piece, no matter what the price of computer systems is at that time. Thus, if inflation exceeds 20\%, you will be paying for the computers less than the 2013-price, whereas if inflation is below 20\%, you will be paying more than the 2013-price. Because you have agreed on a fixed price, your profit level will depend on the rate of inflation.

$50 \%(36 \%)$

Contract B': You agree to buy the computer systems at 2013’s price. Thus, if inflation exceeds $20 \%$, you will pay more than $¥ 4800$, and if inflation is below $20 \%$, you will pay less than $¥ 4800$. Because the prices of both computer systems and financial services are tied to the rate of inflation, your "real" profit will remain essentially the same regardless of the rate of inflation.

$50 \%(64 \%)$

\section{Problem 4-5 (N=67):}

Contracts framed in nominal terms:

Contract C’: You agree to buy the computer systems (in 2013) at $¥ 4800$ a piece, no matter what the price of computer systems is at that time.

60\% (51\%) 
Contract D’: You agree to buy the computer systems at 2013’s price. Thus, instead of buying at $¥ 4800$ for sure, you will pay more if inflation exceeds $20 \%$, and less if inflation is below $20 \%$.

$40 \% \quad(49 \%)$

Problem 4-6 (N=68):

Contracts under a neutral frame:

Contract E’: You agree to buy the computer systems (in 2013) at $¥ 4800$ apiece, no matter what the price of computer systems is at that time.

$58 \%(52 \%)$

Contract F’: You agree to buy the computer systems at 2013’s price. $42 \%(48 \%)$

In the SDT-sample the framing of the problem - either in real, nominal or neutral terms influences respondents' choices between contracts more compared to the MF-sample. A majority of respondents in the Chinese sample prefer the option with a fixed nominal price instead of the option with an indexed price, which is risky in real terms but riskless in nominal terms. This outcome does not depend on the way the contracts are framed or whether the transaction is buying or selling.

In case there is no money illusion, the outcome suggests that the majority of respondents in the Chinese sample exhibit risk-preference. ${ }^{8}$ However, the outcome may also be the result of the interaction between loss (risk) aversion and money illusion. ${ }^{9}$ That is to say

\footnotetext{
${ }^{8}$ In China, which is characterized by unlimited supplies of labor, it would be perfectly rational for a (young) individual to exhibit risk preference.

${ }^{9}$ Loss aversion leads to risk aversion when people evaluate a possible gain because people prefer avoiding losses to making gains.
} 
that a majority of respondents actually do exhibit money illusion, which makes them averse to nominal losses (risks) rather than real losses (risks). This is reflected in (significantly) higher Chi-square scores for the MF-sample compared to the SDT-sample.

As Stephens and Tyran (2012) show, people tend to think of transactions in terms of their nominal (monetary) values. By opting for a guaranteed nominal payout, real risks can be hidden. As loss (risk) aversion is one of the most robust findings to have emerged from behavioral economics, the latter interpretation (money illusion + risk aversion) may be more plausible. ${ }^{10}$ Unfamiliarity with indexed contracts may have played a role as well.

The results of problems 4-1 through 4-6 do not support the notion that respondents in the Chinese sample are less shrouded by the ‘veil of money’ (Irving Fisher, 1896, p.349) compared to respondents in the United States. ${ }^{11,12}$

\section{Mental accounting}

Money illusion may arise from the use of historic cost, which can differ from replacement cost because of a change in the value of money or because of a change in relative prices. With nominal and real prices changing, people's assessment of the value of their possessions may present them with some conflicting intuitions, as illustrated by the following problem that Shafir and Thaler (1996) presented to experienced wine collectors and subscribers to a wine newsletter in the United States. We did not look for wine connoisseurs in China. Judging by Shafir, Diamond and Tversky (1997), however, that should not prejudice the plausibility of our outcome. They presented a variant of the problem to students at Princeton University, which yielded identical results as the problem presented to wine connoisseurs. So, we will do that also for our survey participants in China.

\footnotetext{
${ }^{10}$ Hossain and List (2009) find loss aversion in China.

${ }^{11}$ Klausinger (1990).

${ }^{12}$ Böhm-Bawerk already in 1889 used the term 'Schleier' (i.e. veil) in relation to monetary phenomena in Positive Theorie des Kapitales (Boianovsky, 1993). Schumpeter later used 'Geldschleier’ in his Habilitationsschrift (1908, p.281).
} 


\section{Problem $5(\mathrm{~N}=415):$}

Suppose you bought a case of good 1982 Bordeaux in the futures market for $¥ 160$ a bottle. The wine now sells at auction for about $¥ 600$ a bottle. You have decided to drink a bottle of this wine with dinner.

Which of the following best captures your feeling of the cost to you of drinking this bottle?

$\begin{array}{lll}\text { Costs } ¥ 600 & 48 \% & \text { (20\%) } \\ \text { Doesn’t cost anything } & 25 \% & \text { (30\%) } \\ \text { Feels like saving } ¥ 440 & 27 \% & \text { (25\%) }\end{array}$

The majority of the respondents in the Chinese sample said that the actual cost of drinking the 1982 Bordeaux was less than the replacement cost of the bottle, suggesting considerable money illusion on the part of respondents. However, compared to respondents in the U.S. sample, respondents in the Chinese sample were more than twice as likely to see the replacement cost as the actual cost of drinking the bottle of wine. ${ }^{13}$ This outcome suggests that, although respondents in the Chinese sample are certainly prone to money illusion, they are less so than respondents in the U.S. sample.

\section{Problem $6(\mathrm{~N}=412)$ :}

Two competing bookstores have in stock an identical leather-bound edition of Oscar Wilde’s collected writings. Store A bought its copies for ¥80 each. Liu, who works for Store A, has just sold 100 copies of the book to a local high school for $¥ 176$ a copy.

Store B bought its copies a year after Store A. Because of a 10\% yearly inflation, Store

\footnotetext{
${ }^{13}$ Shafir and Thaler (1996) included two other possibilities (feels like it costs $\$ 20$ (historic cost) and feels like it costs $\$ 20$ plus interest) so the results are not entirely comparable. We corrected for this in the expected frequencies.
} 
B paid ¥88 per copy. Xiao Wu, who works for Store B, has just sold 100 copies of the book to another school for $¥ 180$ a copy.

Who do you think made a better deal selling the books, Liu or Xiao Wu?

Liu $\quad 69 \% \quad(87 \%)$

Xiao $\mathrm{Wu} \quad 31 \% \quad(13 \%)$

A majority of respondents in the Chinese sample perceived Liu, who had a higher profit margin in nominal terms, but a lower profit margin in real terms, as having the better book selling deal. This outcome indicates the prevalence of money illusion. Respondents in the Chinese sample are, however, less likely to be guided by nominal monetary values than by real monetary values compared to respondents in the U.S. sample, which is reflected in the lower Chi-square score (see Section 5).

\section{E. Fairness and morale}

Community standards of fairness appear to have a significant influence on economic behavior. The perception of fairness is expected to impinge on worker morale and, consequently, may have implications for actual job decisions. To explore this issue, we presented respondents in China with the hypothetical scenario below, followed by one of two questions. Half the subjects received the "morale" question, the other half the "job decision" question: 


\section{Problem 7:}

Ablex and Booklink are two publishing firms, each employing a dozen editors. Because the firms are small, unequal raises in salary can create morale problems. In a recent year of no inflation, Ablex gave half its editors a $6 \%$ raise in salary and the other half a $1 \%$ rise. The following year there was $9 \%$ inflation, and Booklink gave half its editors a $15 \%$ raise in salary and the other half a $10 \%$ rise.

\section{Morale $(\mathrm{N}=204)$ :}

In which firm do you think there were likely to be more morale problems?

Ablex $\quad 51 \% \quad(49 \%)$

Booklink: $\quad 27 \%$

Same in both: $21 \%$

$\underline{\text { Job decision }(\mathrm{N}=202):}$

Suppose that an editor who received the lower raise in each firm was then offered a job with a competing company. Which editor do you think was more likely to leave their present position for another job?

The editor who received the lower raise in Ablex

The editor who received the lower raise in Booklink

The two were equally likely
$60 \%$

$7 \%$

$33 \%$
$(57 \%)$

Problem 7 describes two situations where salary raises were the same in real terms, but proportionally different in nominal terms. Virtually to the same extent as respondents in the United States, respondents in the Chinese sample expected morale problems in Ablex, where 
there was a 500 percent difference in salary raises in nominal terms (between 1 percent and 6 percent).

However, there were quite a few respondents in the Chinese sample who expected morale problems at Booklink, where the editors received higher raises in nominal terms and where the difference between the nominal raises was smaller, that is 50 percent. It is unclear what led them to see significantly more morale problems with Booklink compared to Ablex. Perhaps respondents considered the salary raises at Ablex negligible altogether, while the pay rises at Booklink were more ostensible, and hence the difference in pay rises.

Asked subsequently who was more likely to leave his job, the outcome in the U.S. sample and the Chinese sample were nearly identical. Just like in the United States, most respondents in the Chinese sample thought that the editor who received a 1 percent rather than a 6 percent raise would be more likely to leave his present job than the editor who got 10 percent rather than 15 percent. As Shafir, Diamond and Tversky (1997) suggested, money illusion enters into respondents' perceptions of fairness and worker morale, and then naturally extends to their views regarding workers' propensity to quit their present position. Note the striking similarity with problem 1 , where respondents in Chinese sample and respondents in the U.S. sample also gave virtually identical responses to a question pertaining to the likelihood that a worker would decide to quit her job. 
(insert Section 5 here) 


\section{Discussion}

Money illusion seems to be the stepchild of economic theory. Most economists do not even wish to ponder its existence as money illusion ostentatiously violates the rational expectations postulate that has been so central to economic theorizing in the past decades. Recent research, however, shows that money illusion may play a much greater and more disruptive role in the economy than mainstream economists allow for (Brunnermeier and Julliard (2008), Bernanke (2010) and Liu (2010)). Therefore our study, which sheds further light on the phenomenon for China, is well timed.

We find that money illusion is prevalent among respondents in the Chinese sample just as it is among respondents in the U.S. sample. The differences that we find between the Chinese sample and the U.S. sample often suggest a somewhat stronger prevalence of money illusion in the United States. If asked explicitly to evaluate a transaction in terms of happiness or satisfaction instead of economic terms, money illusion among respondents in the Chinese sample is comparable to money illusion among respondents in the U.S. sample.

The Chi-square test has certain shortcomings when testing for money illusion. In Section 5 we conclude, based on the Chi-square score, with regard to problem 3.1. and 3.2 that respondents in the Chinese sample exhibit strong money illusion because purely nominal changes in the price level affect respondents' willingness to buy or sell furniture. However, the Chi-square test does not take into account that buying and selling trigger the same responses (respondents are both more reluctant to by as well as to sell), which is not what is to be expected in case respondents suffer from money illusion. The Chi-square test also does not take into account whether responses are dependent on how the question is framed (i.e. in nominal, real or neutral terms). Sharif, Diamond and Tversky find frame dependency in problem 4.1 - 4.6 and conclude that it was an indication of money illusion. We do not find 
frame dependency in problem 4.1 - 4.6 even though the Chi-square score indicates that money illusion is stronger in the MF sample compared to the SDT sample.

Our overall results show that considerations of happiness, morale and job satisfaction are intimately related with each other, in contrast to economic considerations. The default decision-making framework for respondents in the Chinese sample appears to be more dominated by economic considerations compared to respondents in the United States, who appear more susceptible to considerations of happiness, morale and/or job satisfaction.

This outcome may reflect the difference in affluence between respondents in the United States and China. It suggests that affluent societies may be more prone to money illusion and, hence, more susceptible to irrational exuberance (Akerlof and Shiller, 2009). Given the intricacies of making cross-country comparisons and the fact that our results are not unequivocal, more research is needed to say anything definitive about a potential relationship between affluence and money illusion.

Shafir, Diamond and Tversky (1997) conclude that people attend to nominal value because it is salient, easy to gauge, and in many cases provides a reasonable estimate of real worth. We would like to suggest a fourth motive, that is, that nominal values reflect wellbeing better than real values do. The tendency is likely to persist despite economists’ attempts to educate the public (Fisher, 1928). Shafir et al. amend Solow's model of efficiency wages with money illusion by adding the ratio of the current nominal wage to the previous nominal wage and show that over some range higher inflation will result in a lower real wage (Solow, 1979).

Since the responses to questions pertaining to job attractiveness were comparable in the Chinese sample as in the U.S. sample, money illusion may interfere with the Chinese labor market in a way similar to the U.S. labor market. However, China's labor market in the past decades has broadly been characterized by unlimited supplies of labor, as described in Arthur Lewis’ classic essay 'Economic Development with Unlimited Supplies of Labor’ 
(1954). With laborers working for subsistence wages, it is unlikely that inflation will result in lower real wages, since the (abstract) subsistence wage level is defined as a basket of goods and services rather than in monetary terms.

As far as minimum wage laws apply, inflation may erode real wages in case the minimum wage law does not provide indexation, not necessarily because of money illusion but also in case workers have no bargaining power in an economy with unlimited supplies of labor. Since the spate of wage rises in recent years suggests that the Lewis turning point may soon be reached, the labor market in China soon may share the same characteristics as the U.S. labor market and also be modeled as in Solow's model for efficiency wages added with money illusion, where higher inflation within a certain range will result in lower real wages (Cai and Fang, 2010).

In asset pricing theory both models with nominal variables (nominal interest rate and nominal cash flows) as well as models with real variables (real interest rate and real cash flows) are employed (Chen, Roll and Ross, 1986). Changes in the rate of inflation influence nominal cash flows as well as the nominal rate of interest. To incorporate money illusion in models for asset pricing, we suggest that asset-pricing models should not strictly use either nominal variables or real variables, but a combination of both.

The results of our survey in China are interesting in their own right, but still we believe there are further issues to be examined. First, our survey amounts to a cross section and, given China's rapid development, it would be insightful to carry out similar surveys in future years. When China approaches U.S. economic standards, also in terms of equality and wealth, money illusion may become more prevalent in China. Second, as the degree of money illusion may correspond with economic progress, it would be interesting to see if other emerging economies in, say Africa or South America, give similar survey results. Third, it may be interesting to tie individual responses to individual background characteristics, like 
age, income/wealth and education. Finally, as money illusion can be associated with a few economic conditions that may generate economic downturns, it would be beneficial for China to learn from U.S. experiences, and perhaps carry out educational programs to inform people about money illusion. 


\section{References}

Akerlof, George A. and Robert J. Shiller (2009), Animal Spirits: How Human Psychology

Drives the Economy, and Why It Matters for Global Capitalism, Princeton University Press.

Bernanke, Ben S. (2010), "Monetary Policy and the Housing Bubble,”

http://www.federalreserve.gov/newsevents/speech/bernanke20100103a.htm.

Boianovsky, Maro (1993), “Böhm-Bawerk, Irving Fisher, and the Term "Veil of Money”: A Note,” History of Political Economy, Winter 1993, 25(4): 725-738.

Brunnermeier, Markus K. and Julliard, Christian (2008), “Money Illusion and Housing Frenzies,” Review of Financial Studies, 21 (1). pp. 135-180.

Cai, Fang, and Meiyan Wang (2010), “Growth and Structural Changes in Employment in Transitional China”, Journal of Comparative Economics 38 (2010) 71-81.

Chen, Nai-Fu, Richard Roll and Stephen A. Ross (1986), “Economic Forces and the Stock Market,” The Journal of Business, Vol. 59, No. 3 (Jul., 1986), pp. 383-403.

Daly, Mary, Bart Hobijn, and Brian Lucking (2012), "Why Has Wage Growth Stayed Strong?” FRBSF Economic Letter, April 2, 2012.

Fehr, Ernst, Tyran, Jean-Robert (2001), "Does Money Illusion Matter?" American Economic Review, 91 (5): 1239-1262. 
Fehr, Ernst and Jean-Robert Tyran (2008), “Limited Rationality and Strategic Interaction: The Impact of the Strategic Environment on Nominal Inertia,” Econometrica, 76(2), 353-394.

Fisher, Irving (1928), The Money Illusion, New York: Adelphi Company.

Hong, Fang and Jie Chen (2010), “The Relationship Between Home Mortgage Loan and Real Estate Market in China: Evidences and Insights from a Regional Perspective,” Working Paper.

Hossain, Tanjim and John A. List (2012). "The Behavioralist Visits the Factory: Increasing Productivity Using Simple Framing Manipulations," Management Science, INFORMS, vol. 58(12), pages 2151-2167, December.

Klausinger, Hansjörg (1990), “The Early Use of the Term "Veil of Money" in Schumpeter's Monetary Writings: A Comment on Patinkin and Steiger,” The Scandinavian Journal of Economics, Vol. 92, No. 4 (Dec., 1990), pp. 617-621.

Leontief, Wassily (1936), “The Fundamental Assumptions of Mr. Keynes’ Monetary Theory of Unemployment,” Quarterly Journal of Economics, 5(4):192-7.

Lewis,W. Arthur (1954), “Economic Development with Unlimited Supplies of Labour,” http://www.globelicsacademy.net/2008/2008_lectures/lewis\%20unlimited\%20labor\%20suppl y\%201954.pdf. 
Liu, Renhe (2010), “The Effects of Inflation on China`s Stock Prices: An Explanation Based on Money Illusion Hypothesis,” Working Paper.

Maslow, Abraham H. (1943), “A Theory of Human Motivation,” Psychological Review 50(4) (1943):370-96.

Mees, Heleen (2011), “US Monetary Policy and the Interest Conundrum,” Working Paper, http://www.heleenmees.com/PDF/papers/US_Monetary_Policy.pdf.

Modigliani, Franco, and Richard Cohn (1979), "Inflation, Rational Valuation, and the Market," Financial Analysts Journal, XXXV (1979), 24-44.

Noussair, Charles N., Gregers Richter, and Jean-Robert Tyran (2012), “Money Illusion and Nominal Inertia in Experimental Asset Markets,” Journal of Behavioral Finance, 13(1): 2737.

Okimoto, Daniel I. (2009), “The Financial Crisis and America’s Capital Dependence on Japan and China,” Asia-Pacific Review, Vol. 16, No. 1, 2009.

Patinkin, Don (1965), Money, Interest, and Prices, Harper and Row, New York.

Schumpeter, Joseph A. (1908), Das Wesen und der Hauptinhalt der theoretischen Nationalökonomie, Leipzig:Duncker \& Humblot. 
Shafir, Eldar and Richard H. Thaler (1996), “Invest Now, Drink Later, Spend Never: On the Mental Accounting of Delayed Consumption,” Journal of Economic Psychology, 27 (2006) 694-712.

Shafir, Eldar, Peter A. Diamond and Amos Tversky (1997), "On Money Illusion," Quarterly Journal of Economics, 112 (2): 341-374.

Shiller, Robert J. (1997), “Public Resistance to Indexation: A Puzzle,” Brookings Papers on Economic Activity, Vol. 1997, No. 1 (1997), pp. 159-228.

Solow, Robert M., “Another Possible Source of Wage Stickiness,” Journal of Macroeconomics, I (1979), 9-82.

Stephens, Thomas A. and Jean-Robert Tyran (2012), “““At least I didn’t lose money”: Nominal Loss Aversion Shapes Evaluations of Housing Transactions,” CEPR Discussion Paper No. 9198, October 2012.

Tyran, Jean-Robert (2007), “Money Illusion and the Market,” Science, 317(5841), 1042-1043.

Weber, Bern, Antonio Rangel, Matthias Wibral, Armin Falk and George A. Akerlof (2009), “The Medial Prefrontal Cortex Exhibits Money Illusion,” Proceedings of the National Academy of Sciences of the United States of America, Vol. 106, No. 13 (Mar. 31, 2009), pp. $5025-5028$ 


\section{Acknowledgements}

We would like to thank Eldar Shafir, Peter Diamond and Amos Tversky† for letting us use the 1997 survey for our research in China and making suggestions. We also thank our Chinese assistants, Chao Fang and Andy Xiaoyang. Without their help we would not have been able to do the survey. We would like to offer our gratitude to Min Chum of Ali Baba and Wei Chi of Tsinghua University for providing us access to Ali Baba workers and students at Tsinghua University and Peking University. Finally we want to thank Jean-Robert Tyran for his scrupulous review of our paper and excellent suggestions. 


\section{Appendices}

- $\quad$ In Appendix 1 (a) we present the actual outcomes (frequencies) of the survey held by Shafir, Diamond and Tversky (1997), and the actual outcomes of the survey held by Mees and Franses (2014). Hereafter we will refer to the SDT survey and the MF survey respectively.

- $\quad$ In Appendix 1 (b) we present the expected outcomes (frequencies) under the hypothesis of no-money illusion and $10 \%$ noise in the dataset. That is to say that we assume that even if none of the respondents is susceptible to money illusion, $10 \%$ of respondents will choose an option that does suggest money illusion. In case there are 2 choices, the expected frequencies under the assumption of nomoney illusion show that $90 \%$ of respondents choose the no-money illusion answer and 10\% choose the money illusion answer. In case there are 3 choices, again $90 \%$ of respondents choose the no-money illusion answer, $5 \%$ choose one of the money illusion answers and 5\% choose the other money illusion answer. We have added noise both to make the outcome more realistic as well as for practical reasons. Feedback we received from respondents indicated that they had some difficulty answering the questions. Therefore it seems safe to assume that even if respondents are not susceptible to money illusion, some may still have erred in answering the questions. Others may have been careless in responding. Since we have no feedback on why respondents chose a particular outcome, we can only guess what level of noise is appropriate. Shafir, Diamond and Tversky (1998) did not assume any noise in their dataset, so we have chosen a relatively low level of noise. The practical reason for adding noise is that the Chi-square test can’t be applied to binary outcomes. 
- $\quad$ In Appendix 1 (c) we test whether the actual frequencies in the SDT and MF sample are different from the expected frequencies under the null hypothesis on no-money illusion and 10\% noise in the dataset. Since the SDT and MF-dataset do not have the same sample size, we can't reach conclusions about the relative prevalence of money illusion by comparing the Chi-square score. We only present the score for the no-money illusion answer.

- $\quad$ In Appendix 1 (d) we again test whether the actual frequencies in the SDT and MF sample are different from the expected frequencies under the null hypothesis on no-money illusion and 10\% noise in the dataset. This time we have transformed the MF-dataset in a dataset of the same sample size as the SDT-dataset, so we can reach tentative conclusions about the prevalence of money illusion in the SDTsample compared to the MF sample by comparing the Chi-square scores. A higher Chi-square score indicates in principle more money illusion. We only present the score for the no-money illusion answer. The differences that we find between the Chinese sample and the U.S. sample often suggest a somewhat stronger prevalence of money illusion in the United States. In case we find stronger money illusion in the Chinese sample, viz. problem 3 and 4, the results suggest that there may be an alternative explanation.

- $\quad$ In Appendix 2 (a) we test whether the differences between the scores for the U.S. sample and the Chinese sample are significant. We only present the score for the no-money illusion answer. The differences are in each case significant.

- $\quad$ In Appendix 2 (b) we test whether the results in the SDT sample and the MF sample are different from randomness with a probability 0.5 in case of two choice options and 0.33 in case of three. We only present the score for the no-money illusion answer. The results indicate that respondents did not randomly answer the 
questions. In general, the more 'random' the results, the more susceptible respondents are to money illusion. 


\section{Appendix 1 (a)}

Actual frequencies:

Problem 1:

SDT

Sample Frequency

Economic Terms

Happiness

Job attractiveness

Problem 2:

Rank $1^{\text {st }}$

Rank $2^{\text {nd }}$

Rank $3^{\text {rd }}$

Problem 3:

1

2

$150 \quad 107$

$69 \quad 25$

$139 \quad 90$

SDT

Sample Frequency

$431 \quad 159$

$431 \quad 315$

$431 \quad 155$

SDT

Sample Frequency

362

199

362

152

MF

Sample Frequency

$209 \quad 108$

$202 \quad 138$ 


\begin{tabular}{|c|c|c|c|c|}
\hline \multirow[t]{2}{*}{ Problem 4: } & \multicolumn{2}{|l|}{ SDT } & \multicolumn{2}{|l|}{ MF } \\
\hline & Sample & Frequency & Sample & Frequency \\
\hline 1 & 47 & 38 & 68 & 38 \\
\hline 2 & 49 & 29 & 70 & 33 \\
\hline 3 & 43 & 20 & 69 & 28 \\
\hline 4 & 50 & 32 & 66 & 33 \\
\hline 5 & 47 & 23 & 67 & 27 \\
\hline 6 & 44 & 21 & 68 & 29 \\
\hline \multirow[t]{3}{*}{ Problem 5: } & \multicolumn{2}{|l|}{ SDT } & \multicolumn{2}{|l|}{ MF } \\
\hline & Sample & Frequency & \multicolumn{2}{|c|}{ Sample Frequency } \\
\hline & 76 & 15 & 415 & 199 \\
\hline \multirow[t]{3}{*}{ Problem 6: } & \multicolumn{2}{|l|}{ SDT } & \multicolumn{2}{|l|}{$\mathrm{MF}$} \\
\hline & Sample & Frequency & Sample & Frequency \\
\hline & 130 & 17 & 412 & 128 \\
\hline \multirow[t]{2}{*}{ Problem 7: } & \multicolumn{2}{|l|}{ SDT } & \multicolumn{2}{|l|}{$\mathrm{MF}$} \\
\hline & Sample & Frequency & Sample & Frequency \\
\hline 1 & 362 & 156 & 209 & 44 \\
\hline 2 & 362 & 138 & 202 & 67 \\
\hline
\end{tabular}




\section{Appendix 1 (b)}

Frequencies expected under null hypothesis of no-money illusion with $10 \%$ noise:

Problem 1:

Economic Terms

Happiness

Job attractiveness

Problem 2:

Problem 3:

1

2

Rank $1^{\text {st }}$

Rank $2^{\text {nd }}$

Rank $3^{\text {rd }}$

\section{$\underline{\text { Problem }}$}

SDT

Sample Frequency

$150 \quad 135$

$69 \quad 63$

$139 \quad 125$

SDT

Sample Frequency

$431 \quad 387$

$431 \quad 387$

$431 \quad 387$

SDT

Sample Frequency

$362 \quad 199$

$362 \quad 152$
MF

Sample Frequency

$137 \quad 123$

$138 \quad 124$

$134 \quad 121$

MF

Sample Frequency

$415 \quad 374$

$415 \quad 374$

$415 \quad 374$

MF

Sample Frequency

$209 \quad 188$

$202 \quad 182$ 


\begin{tabular}{|c|c|c|c|c|}
\hline \multirow{2}{*}{ Problem 4: } & \multicolumn{2}{|l|}{ SDT } & \multicolumn{2}{|l|}{$\mathrm{MF}$} \\
\hline & Sample & Frequency & Sample & Frequency \\
\hline 1 & 47 & 42 & 68 & 61 \\
\hline 2 & 49 & 44 & 70 & 63 \\
\hline 3 & 43 & 39 & 69 & 63 \\
\hline 4 & 50 & 45 & 66 & 59 \\
\hline 5 & 47 & 42 & 67 & 60 \\
\hline 6 & 44 & 40 & 68 & 61 \\
\hline \multirow[t]{3}{*}{ Problem 5: } & \multicolumn{2}{|l|}{ SDT } & \multicolumn{2}{|l|}{$\mathrm{MF}$} \\
\hline & Sample & Frequency & Sample & Frequency \\
\hline & 76 & 68 & 415 & 374 \\
\hline \multirow[t]{3}{*}{ Problem 6: } & \multicolumn{2}{|l|}{ SDT } & \multicolumn{2}{|l|}{$\mathrm{MF}$} \\
\hline & Sample & Frequency & Sample & Frequency \\
\hline & 130 & 117 & 412 & 371 \\
\hline \multirow[t]{2}{*}{ Problem 7: } & \multicolumn{2}{|l|}{ SDT } & \multicolumn{2}{|l|}{$\mathrm{MF}$} \\
\hline & Sample & Frequency & Sample & Frequency \\
\hline 1 & 72 & 5 & 204 & 184 \\
\hline 2 & 72 & 5 & 202 & 182 \\
\hline
\end{tabular}




\section{Appendix 1 (c)}

We now use the non-parametric Pearson Chi-square tests with exact two-sided p values (as computed using IBM SPSS Statistics software, version 20) to test whether the frequencies in SDT \& MF different from the frequencies under the null hypothesis on no-money illusion.

The tests are based on the actual frequencies (and not on the fractions). Each time we present the Chi-square test value (with the exact $\mathrm{p}$ value in parentheses). As a rule of thumb, $\mathrm{p}<$ 0.001 indicates that the conclusion that the result is different from the null-hypothesis of nomoney illusion is very reliable while $\mathrm{p}<0.05$ indicates that the conclusion is reliable.

$\begin{array}{lll}\text { Problem 1: } & \text { SDT } & \text { MF } \\ \text { Economic Terms } & 58.07(0.000) & 10.36(0.000) \\ \text { Happiness } & 221.6(0.000) & 396.8(0.000) \\ \text { Job attractiveness } & 462.9(0.000) & 449.2(0.000) \\ & & \\ \text { Problem 2: } & \text { SDT } & \text { MF } \\ \text { Rank 1 } & & 349.9(0.000) \\ \text { Rank 2 } & & \\ \text { Rank } 3^{\text {rd }} & 2153(0.000) & 53.08(0.000) \\ & 157.9(0.000) & 201.7(0.000) \\ \text { Problem 3: } & 1840(0.000) & 1080(0.000) \\ 1 & & \text { MF } \\ 2 & \text { SDT } & 1779(0.000)\end{array}$




\section{Problem 4:}

1

2

3

4

5

6

Problem 5:

Problem 6:

Problem 7:

1

2
SDT

$4.371(0.037)$

$51.70(0.000)$

$63.69(0.000)$

$37.56(0.000)$

$88.06(0.000)$

$87.36(0.000)$

SDT

$347.2(0.000)$

SDT

$854.7(0.000)$

SDT

$293.1(0.000)$

$410.6(0.000)$
MF

$180.0(0.000)$

$142.9(0.000)$

$187.2(0.000)$

$117.3(0.000)$

$183.9(0.000)$

$169.4(0.000)$

MF

$816.8(0.000)$

MF

$1589(0.000)$

MF

$1163(0.000)$

$1291(0.000)$ 


\section{Appendix 1 (d)}

We now use the non-parametric Pearson Chi-square tests with exact two-sided p values (as computed using IBM SPSS Statistics software, version 20) to test whether the frequencies in SDT \& MF different from the frequencies under the null hypothesis of no-money illusion. The tests are based on the actual frequencies (and not on the fractions), with the MF-dataset being transformed into a dataset with the same sample size as the SDT-dataset. Each time we

present the Chi-square test value (with the exact $\mathrm{p}$ value in parentheses). As a rule of thumb, $\mathrm{p}$ $<0.001$ indicates that the conclusion that the result is different from the null-hypothesis of nomoney illusion is very reliable while $\mathrm{p}<0.05$ indicates that the conclusion is reliable.

$\begin{array}{lll}\text { Problem 1: } & \text { SDT } & \text { MF } \\ \text { Economic Terms } & 58.07(0.000) & 10.67(0.001) \\ \text { Happiness } & 221.6(0.000) & 198.4(0.000) \\ \text { Job attractiveness } & 462.9(0.000) & 462.9(0.000) \\ & & \\ \text { Problem 2: } & \text { SDT } & \text { MF } \\ \text { Rank 1 } & 369.5(0.000) \\ \text { Rank 2 } & \\ \text { Rank } 3^{\text {rd }} & 2153(0.000) & 54.96(0.000) \\ & 157.9(0.000) & 193.7(0.000) \\ \text { Problem 3: } & 1840(0.000) & 1887(0.000) \\ 1 & & 3154(0.000) \\ 2 & \text { SDT } & \text { MF }\end{array}$




\section{Problem 4:}

1

2

3

4

5

6

Problem 5:

Problem 6:

Problem 7:

1

2
SDT

$4.371(0.037)$

$51.70(0.000)$

$63.69(0.000)$

$37.56(0.000)$

$88.06(0.000)$

$87.36(0.000)$

SDT

$347.2(0.000)$

SDT

$854.7(0.000)$

SDT

$293.1(0.000)$

$410.6(0.000)$
MF

$128.3(0.000)$

$101.0(0.000)$

$133.2(0.000)$

$88.89(0.000)$

$128.3(0.000)$

$117.8(0.000)$

MF

$154.0(0.000)$

MF

$506.8(0.000)$

MF

$412.5(0.000)$

$457.4(0.000)$ 


\section{Appendix 2 (a)}

We now use the non-parametric Pearson Chi-square tests with exact two-sided p values (as computed using IBM SPSS Statistics software, version 20) to test whether the results differ from randomness with a probability 0.5 in case of two choice options and 0.33 in case of three. The tests are based on the actual frequencies (and not on the fractions). Each time we present the Chi-square test value (with the exact $\mathrm{p}$ value in parentheses). As a rule of thumb, $\mathrm{p}$ $<0.001$ indicates that the conclusion that the result is different from randomness is very reliable while $\mathrm{p}<0.05$ indicates that the conclusion is reliable.

\begin{tabular}{|c|c|c|}
\hline Problem 1: & SDT & MF \\
\hline Economic Terms & $27.307(0.000)$ & $55.248(0.000)$ \\
\hline Happiness & 5.232 (0.029) & $6.522(0.013)$ \\
\hline Job attractiveness & $12.094(0.001)$ & $11.940(0.001)$ \\
\hline Problem 2: & SDT & MF \\
\hline Rank $1^{\text {st }}$ & $122.858(0.000)$ & $182.810(0.000)$ \\
\hline $\operatorname{Rank} 2^{\text {nd }}$ & $309.624(0.000)$ & $407.745(0.000)$ \\
\hline Rank $3^{\text {rd }}$ & $67.619(0.000)$ & $251.687(0.000)$ \\
\hline Problem 3: & SDT & MF \\
\hline 1 & $129.188(0.000)$ & $34.804 \quad(0.000)$ \\
\hline 2 & $55.315 \quad(0.000)$ & $111.366(0.000)$ \\
\hline
\end{tabular}




\section{Problem 4:}

1

2

3

4

5

6

Problem 5:

Problem 6:

Problem 7:

1

2
SDT

$17.894(0.000)$

$1.653(0.253)$

$0.209 \quad(0.761)$

$3.920(0.065)$

$0.021 \quad(1.000)$

$0.091 \quad(0.880)$

SDT

$1.684(0.452)$

SDT

$70.892(0.000)$

SDT

$20.853(0.000)$

$29.083(0.000)$
MF

$40.140(0.000)$

MF

2.118 (0.182)

$0.229(0.720)$

$2.449(0.148)$

$0.000 \quad(1.000)$

$2.522(0.142)$

$1.471 \quad(0.275)$

MF

$59.068(0.000)$

MF

$29.324(0.000)$

$85.020(0.000)$ 


\section{Appendix 2 (b)}

We now use the non-parametric Pearson Chi-square tests with exact two-sided p values (as computed using IBM SPSS Statistics software, version 20) to test whether the result in the MF sample are different from the result in the SDT sample. The tests are based on the actual frequencies (and not on the fractions), albeit that the MF samples are transformed in samples with the same size as the SDT-sample so the p values are comparable. Each time we present the Chi-square test value (with the exact $\mathrm{p}$ value in parentheses). As a rule of thumb, $\mathrm{p}<$ 0.001 indicates that the conclusion that the result in the MF sample is different from the SDT sample is very reliable while $\mathrm{p}<0.05$ indicates that the conclusion is reliable.

Problem 1:

Economic Terms

Happiness

Job attractiveness

Problem 2:

Rank $1^{\text {st }}$

Rank $2^{\text {nd }}$

Rank $3^{\text {rd }}$

Problem 3:

1
$4.299(0.051)$

$0.164 \quad(0.762)$

0.001 (1.000)

$83.333(0.000)$

$5.763(0.000)$

$136.862(0.000)$

$42.415(0.000)$

$164.841(0.000)$ 
Problem 4:

1

2

3

4

5

6

Problem 5:

Problem 6:

Problem 7:

1

2
$17.889(0.000)$

$1.675(0.263)$

$1.780 \quad(0.242)$

2.263 (0.186)

$0.837 \quad(0.444)$

0.279 (0.698)

$23.540(0.000)$

$16.323(0.000)$

$16.934(0.000)$

$0.522(0.795)$ 


\section{Table with core results}

\begin{tabular}{|c|c|c|c|c|c|c|c|}
\hline & $I^{1}$ & $\mathrm{II}^{1}$ & $\mathrm{III}^{2}$ & $\mathrm{IV}^{2}$ & $\mathrm{~V}^{3}$ & $\mathrm{VI}^{4}$ & $\mathrm{VII}^{4}$ \\
\hline Problem & $\begin{array}{c}\text { SDT } \\
\text { money illusion }\end{array}$ & $\begin{array}{c}\text { MF } \\
\text { money illusion }\end{array}$ & SDT & MF & SDT versus MF & $\begin{array}{l}\mathrm{SDT} \neq \\
\text { random }\end{array}$ & $\begin{array}{l}\mathrm{MF} \neq \\
\text { random }\end{array}$ \\
\hline $\begin{array}{c}1.1 \\
\text { Salary } \\
\text { Economic terms }\end{array}$ & $58.07(0.000)$ & $10.67(0.001)$ & weak & weak & $\begin{array}{l}\text { SDT }>\text { MF } \\
\mathrm{p}=0.051\end{array}$ & 0.000 & 0.000 \\
\hline $\begin{array}{c}1.2 \\
\text { Salary } \\
\text { Happiness } \\
\end{array}$ & $221.6(0.000)$ & $198.4(0.000)$ & medium & medium & $\begin{array}{l}\text { SDT }>M F \\
p=0.762\end{array}$ & 0.029 & 0.013 \\
\hline $\begin{array}{c}1.3 \\
\text { Salary } \\
\text { Job decision }\end{array}$ & $462.9(0.000)$ & $462.9(0.000)$ & medium & medium & $\begin{array}{l}\mathrm{SDT}=\mathrm{MF} \\
\mathrm{p}=1.000\end{array}$ & 0.001 & 0.001 \\
\hline $\begin{array}{c}2.1 \\
\text { Transaction } \\
\text { Rank } 1^{\text {st }}\end{array}$ & $2153(0.000)$ & $369.5(0.000)$ & medium & weak & $\begin{array}{l}\text { SDT }>M F \\
p=0.000\end{array}$ & 0.000 & 0.000 \\
\hline $\begin{array}{c}2.2 \\
\text { Transaction } \\
\text { Rank } 2^{\text {nd }}\end{array}$ & $157.9(0.000)$ & $54.96(0.000)$ & weak & weak & $\begin{array}{l}\text { SDT }>\text { MF } \\
p=0.000\end{array}$ & 0.000 & 0.000 \\
\hline $\begin{array}{c}2.3 \\
\text { Transaction } \\
\text { Rank } 3^{\text {rd }}\end{array}$ & $1840(0.000)$ & $193.7(0.000)$ & medium & weak & $\begin{array}{l}\text { SDT }>\text { MF } \\
p=0.000\end{array}$ & 0.000 & 0.000 \\
\hline $\begin{array}{c}3.1 \\
\text { Transaction } \\
\text { Buying }\end{array}$ & $846.2(0.000)$ & $1887(0.000)$ & medium & strong & $\begin{array}{l}\text { SDT }<\text { MF } \\
\mathrm{p}=0.000\end{array}$ & 0.000 & 0.000 \\
\hline $\begin{array}{c}3.2 \\
\text { Transaction } \\
\text { Selling }\end{array}$ & $1214(0.000)$ & $3154(0.000)$ & medium & strong & $\begin{array}{l}\text { SDT }<\text { MF } \\
\mathrm{p}=0.000\end{array}$ & 0.000 & 0.000 \\
\hline $\begin{array}{c}4.1^{*} \\
\text { Contract } \\
\text { Selling, real }\end{array}$ & $4.371(0.037)$ & $128.3(0.000)$ & weak & medium & $\begin{array}{l}\text { SDT }<M F \\
p=0.000\end{array}$ & 0.000 & 0.182 \\
\hline $\begin{array}{c}4.2^{*} \\
\text { Contract } \\
\text { Selling, nominal }\end{array}$ & $51.70(0.000)$ & $101.0(0.000)$ & medium & medium & $\begin{array}{l}\mathrm{SDT}<\mathrm{MF} \\
\mathrm{p}=0.263\end{array}$ & 0.253 & 0.720 \\
\hline
\end{tabular}




\begin{tabular}{|c|c|c|c|c|c|c|c|}
\hline $\begin{array}{c}4.3^{*} \\
\text { Contract } \\
\text { Selling, neutral }\end{array}$ & $63.69(0.000)$ & $133.2(0.000)$ & medium & medium & $\begin{array}{l}\text { SDT }<\text { MF } \\
\mathrm{p}=0.242\end{array}$ & 0.761 & 0.148 \\
\hline $\begin{array}{c}4.4^{*} \\
\text { Contract } \\
\text { Selling, real }\end{array}$ & $37.56(0.000)$ & $88.89(0.000)$ & weak & medium & $\begin{array}{l}\text { SDT }<\text { MF } \\
\mathrm{p}=0.186\end{array}$ & 0.065 & 1.000 \\
\hline $\begin{array}{c}4.5^{*} \\
\text { Contract } \\
\text { Selling, nominal }\end{array}$ & $88.06(0.000)$ & $128.3(0.000)$ & medium & medium & $\begin{array}{l}\text { SDT }<\text { MF } \\
p=0.444\end{array}$ & 1.000 & 0.142 \\
\hline $\begin{array}{c}4.6^{*} \\
\text { Contract } \\
\text { Selling, neutral }\end{array}$ & $87.36(0.000)$ & $117.8(0.000)$ & medium & medium & $\begin{array}{l}\text { SDT }<\text { MF } \\
p=0.698\end{array}$ & 0.880 & 0.275 \\
\hline $\begin{array}{c}5 \\
\text { Mental accounting }\end{array}$ & $347.2(0.000)$ & $154.0(0.000)$ & strong & medium & $\begin{array}{l}\text { SDT }>\text { MF } \\
\mathrm{p}=0.000\end{array}$ & 0.452 & 0.000 \\
\hline $\begin{array}{c}6 \\
\text { Mental accounting }\end{array}$ & $854.7(0.000)$ & $506.8(0.000)$ & strong & medium & $\begin{array}{l}\text { SDT }>\text { MF } \\
p=0.000\end{array}$ & 0.000 & 0.000 \\
\hline $\begin{array}{c}7.1 \\
\text { Fairness \& morale } \\
\text { Work morale }\end{array}$ & $293.1(0.000)$ & $412.5(0.000)$ & medium & strong & $\begin{array}{l}\text { SDT }<\text { MF } \\
p=0.000\end{array}$ & 0.000 & 0.000 \\
\hline $\begin{array}{c}7.2 \\
\text { Fairness \&morale } \\
\text { Job decision }\end{array}$ & $410.6(0.000)$ & $457.4(0.000)$ & medium & medium & $\begin{array}{l}\text { SDT }<\text { MF } \\
\mathrm{p}=0.795\end{array}$ & 0.000 & 0.000 \\
\hline
\end{tabular}

${ }^{1}$ Columns I and II present the Chi-square score and p values for the test whether the frequencies in the SDT sample and MF sample differ from the expected frequencies under the null hypothesis of no-money illusion. A higher Chi-square score indicates stronger money illusion. The scores in columns I and II can be compared, but the scores for the various (sub)problems can not be compared, because the sample size is different for each (sub)problem.

${ }^{2}$ Columns III and IV give a qualitative assessment of the level of money illusion. Money illusion is deemed strong if less than 30 percent of respondents choose the no-money illusion option, it is deemed medium if between 30 an 60 percent of respondents choose the no-money illusion option and weak if 60 percent or more of respondents choose the no-money illusion option.

${ }^{3}$ Column V compares the level of money illusion in the MF sample to the SDT sample. As a rule of thumb, $\mathrm{p}<0.001$ indicates that the conclusion is very reliable while $\mathrm{p}<$ 0.05 indicates that the conclusion is reliable.

${ }^{4}$ Columns VI and VII test whether the results for respondents in the SDT sample and the MF sample are different from randomness with a probability 0.5 in case of two choice options and 0.33 in case of three.

${ }^{*}$ Characterization of the results depends on the assumption of risk aversion. 